\title{
Improved therapeutic efficacy of unmodified anti-tumor antibodies by immune checkpoint blockade and kinase targeted therapy in mouse models of melanoma
}

\author{
Rolando Pérez-Lorenzo ${ }^{1}$, Stephanie O. Erjavec ${ }^{1,2}$, Angela M. Christiano ${ }^{1,2}$ and \\ Raphael Clynes ${ }^{3}$ \\ ${ }^{1}$ Department of Dermatology, Columbia University, New York, NY 10032, USA \\ ${ }^{2}$ Department of Genetics and Development, Columbia University, New York, NY 10032, USA \\ ${ }^{3}$ Department of Medicine, Columbia University, New York, NY 10032, USA \\ Correspondence to: Angela M. Christiano, email: amc65@cumc.columbia.edu \\ Keywords: anti-tumor antibodies; targeted therapy; immunotherapy; combination therapies; melanoma \\ Received: August 14, $2020 \quad$ Accepted: December 29, $2020 \quad$ Published: January 19, 2021
}

Copyright: ( 2021 Pérez-Lorenzo et al. This is an open access article distributed under the terms of the Creative Commons Attribution License (CC BY 3.0), which permits unrestricted use, distribution, and reproduction in any medium, provided the original author and source are credited.

\section{ABSTRACT}

The use of specific anti-tumor antibodies has transformed the solid cancer therapeutics landscape with the relative successes of therapies such as anti-HER2 in breast cancer, and anti-EGFR in HNSCC and colorectal cancer. However, these therapies result in toxicity and the emergence of resistant tumors. Here, we showed that removing immune suppression and enhancing stimulatory signals increased the anti-tumor activity of unmodified TA99 antibodies (anti-TYRP1) with a significant reduction of growth of solid tumors and lung metastases in mouse models of melanoma. Immune checkpoint blockade enhanced the efficacy of TA99, which was associated with greater $\mathrm{CDB}^{+} / \mathrm{Foxp}^{+}, \mathrm{NK1.1}^{+}$and dendritic cell infiltrates, suggestive of an increased anti-tumor innate and adaptive immune responses. Further, MEK inhibition in melanoma cell lines increased the expression of melanosomal antigens in vitro, and combining TA99 and MEKi in vivo resulted in enhanced tumor control. Moreover, we found an improved therapeutic effect when YUMM tumor-bearing mice were treated with TA99 combined with MEKi and immune checkpoint blockade (antiPD1 and anti-CTLA4). Our findings suggest that MEKi induced an increased expression of tumor-associated antigens, which in combination with anti-tumor antibodies, generated a robust adaptive anti-tumor response that was sustained by immune checkpoint inhibition therapy. We postulate that combining anti-tumor antibodies with standard-of-care strategies such as immune checkpoint blockade or targeted therapy, will improve therapeutic outcomes in cancer.

\section{INTRODUCTION}

It is well accepted that tumor development and progression is usually controlled by immunosurveillance mechanisms in which specific and non-specific immunological responses are constantly mounted against tumor cells [1]. Growing evidence points toward a correlation between high immunogenicity and immune responsiveness of tumors [2]. In melanoma, this concept is supported by findings such as spontaneous remissions, the existence of metastatic tumors without identifiable primary lesions, and the presence of infiltrating $\mathrm{T}$ lymphocytes capable of recognizing melanoma-derived antigens in primary tumors and metastatic lesions [3, 4].

The treatment of certain cancers has been transformed by the use of specific anti-tumor antibody therapeutics, including FDA-approved monoclonal antibodies for the treatment of breast, colon [5], head and neck [6], multiple myeloma [7], chronic lymphocytic leukemia [8], and non-Hodgkin's lymphoma [9]. Nevertheless, clinical remissions are infrequent and transient in advanced stage solid tumors treated with anti-tumor antibodies, even with concomitant chemotherapy 
$[10,11]$. Early clinical successes with anti-tumor antibody therapy (anti-CD20, anti-HER2, anti-EGFR) were exclusively attributed to the interruption of their respective signaling pathways, but recent evidence suggests an essential role for innate as well as adaptive immunity in the therapeutic outcome.

Passive administration of anti-tumor antibodies generally functions by targeting malignant cells through IgGmediated antibody-dependent cellular cytotoxicity (ADCC), which is a rapid but relatively short-acting anti-tumor response. Alternatively, we and others also demonstrated that the administration of anti-tumor antibodies induces longlasting FcR-dependent tumor specific immunity in the host, with kinetics consistent with an induced adaptive immune response against the tumor $[12,13]$. In this model, anti-tumor antibodies, alone or in combination with chemotherapy, will promote innate cell-mediated ADCC (e.g., macrophages), and the capture and processing of antigens by antigen presenting cells (APC), with the subsequent stimulation and homing of antigen-specific effector T lymphocytes to the tumor site, leading to tumor elimination, a phenomenon we and others referred to as the "vaccinal effect" [12-14].

However, the activation of adaptive immune responses is also strictly regulated in vivo by inhibitory signaling pathways, which can be hijacked by successful tumor cells as an immune evasion mechanism. In order to overcome these regulatory mechanisms, different therapeutic strategies using antibody-mediated immune checkpoint blockade (ICB; i.e., anti-CTLA4 and antiPD1) have had a profound impact in anti-cancer therapy by improving survival [15].

Here, we investigated the potential of currently available targeted therapies and ICB to enhance the therapeutic efficacy of unmodified anti-tumor antibodies. With the use of the B16 and YUMM mouse models of melanoma and the anti-TYRP1 mouse monoclonal antibody TA99, we demonstrated that the therapeutic effects of these unmodified anti-tumor antibodies can be enhanced by ICB (anti-PD1 and anti-CTLA4 monoclonal antibodies) through the stimulation of both innate and adaptive anti-tumor immune responses. In addition, we found that the MEK inhibitor (trametinib)-induced increased expression of melanosomal antigens further enhanced the anti-melanoma response to combination therapy with anti-tumor antibodies and immune checkpoint blockade in mouse models of melanoma.

\section{RESULTS}

\section{Elimination of $T$ regulatory cells enhances the efficacy of TA99 antibodies in the B16 mouse melanoma model}

The passive administration of anti-tumor antibodies activates adaptive tumor specific immunity in the host, which can be downregulated by tumor-regulated inhibitory processes such as the accumulation of Treg cells. Thus, to enhance the therapeutic effects of anti-tumor antibodies by removing immune suppressive regulatory signals, we first tested the combination of anti-tumor antibodies [TA99; anti- tyrosinase-related protein-1 (TYRP1) monoclonal antibodies] with antibody-mediated depletion of Treg cells in the B16 mouse model of melanoma. Seven-week-old female C57BL/6 mice were inoculated with $5 \times 10^{4} \mathrm{~B} 16$ cells (B16) in the right flank (s.c.), and injected (i.p.) with TA99 monoclonal antibodies (mAb) on days 5 and 7 after tumor inoculation and a single dose of Treg depleting antibodies [anti-CD25 (PC61 mAb)] on day 14 (Figure 1A). Seven days after a single dose of PC61, we observed a significant depletion of $\mathrm{CD} 25^{+} \mathrm{T}$ cells in the spleen of treated mice (Supplementary Figure 1A). Administration of TA99 in combination with antibody-mediated depletion of Treg cells resulted in a significant reduction in subcutaneous B16 melanoma growth $(p<0.0001)$ (Figure 1B and 1C). Treatment with PC61 mAb, alone or in combination with TA99 antibodies, resulted in the expected reduction in Treg cells infiltrating tumors (Figure 1D). We did not observe a significant difference in $\mathrm{CD} 4^{+}$or $\mathrm{CD} 8^{+}$cells infiltrating these tumors; but there was a decreased Foxp3/CD8 ratio in tumors treated with PC61 (Figure 1D). These tumors did not show diminished proliferation as demonstrated by Ki67 immunostaining (Supplementary Figure 1B), suggesting increased tumor cell death. In contrast, depletion of $\mathrm{CD} 25^{+}$cells shortly after tumor injection (day 4) resulted in increased tumor growth with no synergistic effect with TA99 administered on days 5 and 7 as observed before (Supplementary Figure 1C and 1D).

We also tested the combination of TA99 with PC61 in the B16 mouse model of lung metastases. After intravenous inoculation of $2 \times 10^{5} \mathrm{~B} 16$ tumor cells, we administered monotherapy and combination therapy with TA99 and PC61 according to the schedule shown in Figure 1A. Briefly, TA99 was administered (i.p.) on days 5 and 7 after tumor cell injection, and a single dose of PC61 was administered on day 14 post-tumor inoculation. On day 21 post-tumor cell inoculation, the lungs were harvested and fixed in Fekete's solution and tumors counted blindly under a dissection scope. The combination of TA99/PC61 resulted in a significant reduction in the burden of pigmented nodules in the lungs $(p=0.002)$ (Figure $1 \mathrm{E}$ and $1 \mathrm{~F})$ without any significant changes in tumor burden in the monotherapy groups. Taken together, these results show that elimination of immunosuppressive signals from $T$ regulatory cells after passive administration of specific anti-tumor antibodies improved the therapeutic outcome in the B16 melanoma models of solid tumors and lung metastases.

\section{Anti-4-1BB/CD137 agonistic mAb increases the anti-tumor effects of TA99 in B16 mouse melanoma}

We observed that treatment of mice bearing subcutaneous melanomas with TA99 resulted in an increase 
in $4-1 \mathrm{BB}^{+}$cells infiltrating the tumors (Supplementary Figure 2), suggesting that these tumors may be amenable to immunotherapy with anti-4-1BB agonist mAb, which may also enhance the anti-tumor effects of TA99 when administered in combination. Thus, we treated subcutaneous B16 mouse melanomas with TA99, anti-4-1BB agonist $\mathrm{mAb}$, or the combination, starting on day 5 after tumor inoculation (Figure 2A), and followed tumor growth for up to 21 days. The combination therapy with TA99 and anti-41BB agonistic $\mathrm{mAb}$ resulted in eradication of subcutaneous B16 melanomas (Figure 2B). In contrast, no effect on tumor growth was observed when these mAbs were given as single-agent therapy. Furthermore, the combination of TA99 with anti-4-1BB mAb also resulted in a significant reduction in tumor size when treatment was started after the subcutaneous B16 tumors reached a volume between 65 and $80 \mathrm{~mm}^{3}$ (Figure 2C). Thus, eliminating regulatory events (via antibody-mediated Treg depletion; Figure 1) or inducing activation of immune effectors (using anti-4-1BB agonistic $\mathrm{mAb}$; Figure 2), enhanced the therapeutic effects of the TA99 anti-tumor monoclonal antibody (anti-TYRP1) in the B16 mouse model of melanoma.

\section{Immune checkpoint blockade increases the efficacy of TA99 mAb in the B16 model of melanoma}

Therapy with immune checkpoint blockers such as ipilimumab (anti-CTLA4), and nivolumab and pembrolizumab (anti-PD1), has been established as the standard-of-care for melanoma with a significant improvement in OS. Blockade of CTLA4 has proven effective in melanoma and other tumors, and has a profound effect on the Treg population. We found that elimination of Treg cells improves the efficacy of TA99 in the B16 model of melanoma. Thus, to test the hypothesis that the elimination of regulatory signals by immune checkpoint blockade have an enhanced therapeutic effect with anti-tumor antibodies, we treated C57BL/6 mice bearing subcutaneous B16 tumors with TA99 mAb in combination with anti-immune checkpoint mAbs including anti-PD1 (Programmed Death 1) and/or anti-CTLA4 (Cytotoxic T Lymphocyte Associated antigen 4; IgG2b depleting antibody) as indicated (Figure 3A). Singleagent treatment with TA99 or either of the anti-immune checkpoint $\mathrm{mAbs}$ alone induced a modest reduction in subcutaneous melanoma tumor size (Figure 3B). However, when we tested combination treatment with TA99 and either anti-CTLA4 or anti-PD1, we observed a significant reduction in tumor growth compared to control animals or those that received monotherapy (Figure 3B). Furthermore, considering that current standard-of-care strategies in melanoma often include a combination of anti-PD1 and anti-CTLA4 therapy, we treated B16 tumor bearing mice with this double combination. We observed a significant reduction in volume when compared with the control or the single treatment groups $(p<0.0001)$. In order to investigate whether the administration of the combination of ICB further enhance the therapeutic effect of TA99, we tested the triple combination. Here, we observed the complete eradication of tumors (Figure 3B), demonstrating that the combined ICB therapy dramatically enhanced the therapeutic efficacy of TA99 antibodies in melanoma.

We next analyzed the composition of the immune infiltrates in tumors treated with TA99 in combination with anti-PD1 or anti-CTLA4 by flow cytometry (Figure 3C and 3D and Supplementary Figure 3). Tumors treated with TA99/anti-CTLA4 showed an increase in $\mathrm{CD}^{+}$cells and the $\mathrm{CD}^{+} / \mathrm{Foxp}^{+}$cell ratio (Figure $3 \mathrm{C}$ ). In addition, this combination resulted in a greater infiltration of $\mathrm{NK} 1.1^{+}$ cells; however, a similar increase was reached when the single-agent therapy with TA99, anti-CTLA4 and antiPD1was used alone (Figure 3C and 3D). Furthermore, treatment with TA99 alone and in combination with antiCTLA4, but not anti-CTLA4 alone, induced an increase in the percent of dendritic cells $\left(\mathrm{CD} 11 \mathrm{~b}^{+} \mathrm{CD} 11 \mathrm{c}^{+}\right)$infiltrating B16 subcutaneous melanomas (Figure 3C).

When we treated B16 tumors with anti-PD1 antibodies, we observed an increased $\mathrm{CD} 8^{+}$infiltrate that was also reflected as an increase in the $\mathrm{CD} 8^{+} / \mathrm{Foxp}^{+}$cell ratio. We also found an increase in the dendritic cells infiltrating these tumors. However, no additional increase was found when the combination of TA99/anti-PD1 was tested (Figure 3D). We did not find differences in $\mathrm{B}$ cells $\left(\mathrm{CD} 19^{+}\right), \mathrm{CD}^{+} \mathrm{T}$ cells or G-MDSC $\left(\mathrm{CD} 11 \mathrm{~b}^{+} \mathrm{Gr}-1^{+}\right)$ (Figure 3C and 3D) in any of the experimental groups. These observations suggest that DC and their antigen presentation capabilities, as well as the potential activation of $\mathrm{CD}^{+} \mathrm{T}$ cells, may play a role in the increased antitumor effect of the therapeutic combinations tested.

Additionally, we tested the combination of TA99 with ICB in the B16 model of lung metastases (Figure 4). Treatment with TA99, anti-CTLA4 (Figure 4A) or antiPD1 (Figure 4B) mAbs as single agents did not show any significant difference in tumor burden between groups or when compared with untreated controls. However, the combination treatment with TA99 and blockade of CTLA4 resulted in a significant reduction in the number of melanomas in the lungs of the majority $(4 / 5)$ of treated animals (Figure 4A). In addition, as expected, treatment with a combination of anti-CTLA4 and anti-PD1 mAb reduced the number of lung metastases in all the animals, however, we did not observe additional reduction in lung metastases as a result of a triple combination with TA99 (Supplementary Figure 4).

\section{MEK inhibition enhances the therapeutic efficacy of TA99 anti-tumor antibodies in B16 and BRAF mutant mouse melanomas}

It has been established that inhibition of the MAPK pathway with BRAF and MEK inhibitors induces de- 
differentiation of BRAF mutant human melanoma cells. This process is characterized by an increased expression of melanosomal antigens, including TYRP1, the target for TA99 antibodies. Thus, we next tested the in vitro effects of MEK inhibitors (MEKi) on B16 cell viability by MTS assays. Selumetinib (AZD6244) and trametinib partially reduced the viability of B16 in a dose dependent manner (Supplementary Figure 5A). We also found a dose-dependent increase in the levels of both TYRP1 and MITF (melanosomal antigens) upon treatment of B16 cells with either selumetinib (6 h) or trametinib (24 h), which correlated with an effective downregulation of the MAPK pathway as demonstrated by dephosphorylation of ERK (Figure 5A). Furthermore, treatment with the MEKi trametinib induced increased pigmentation in B16 mouse melanoma cells (Figure 5B and Supplementary Figure 5B).
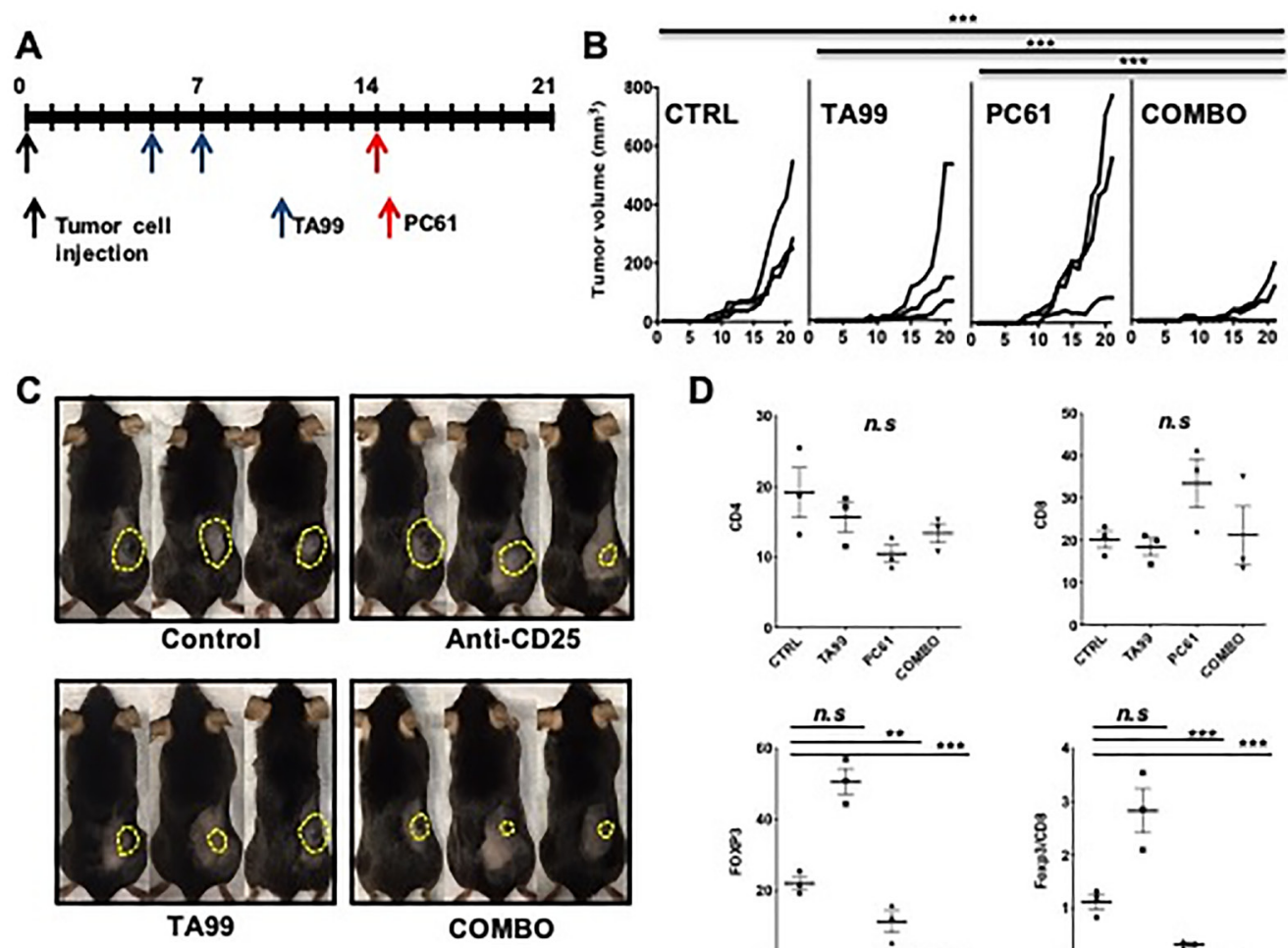

D
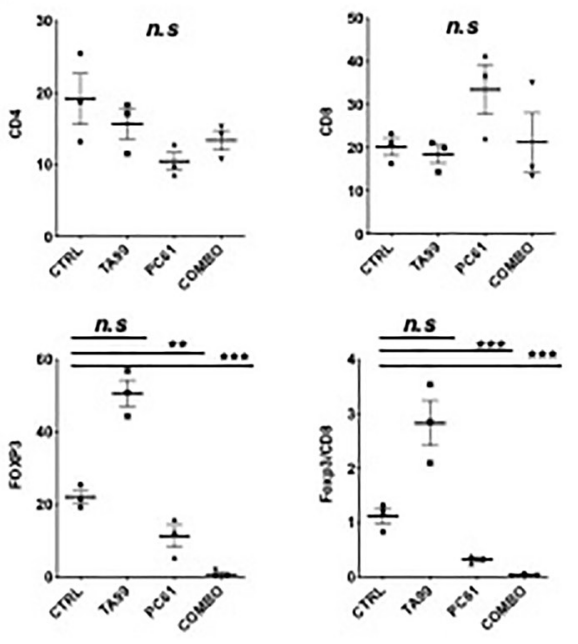

$\mathbf{E}$

$\mathbf{F}$
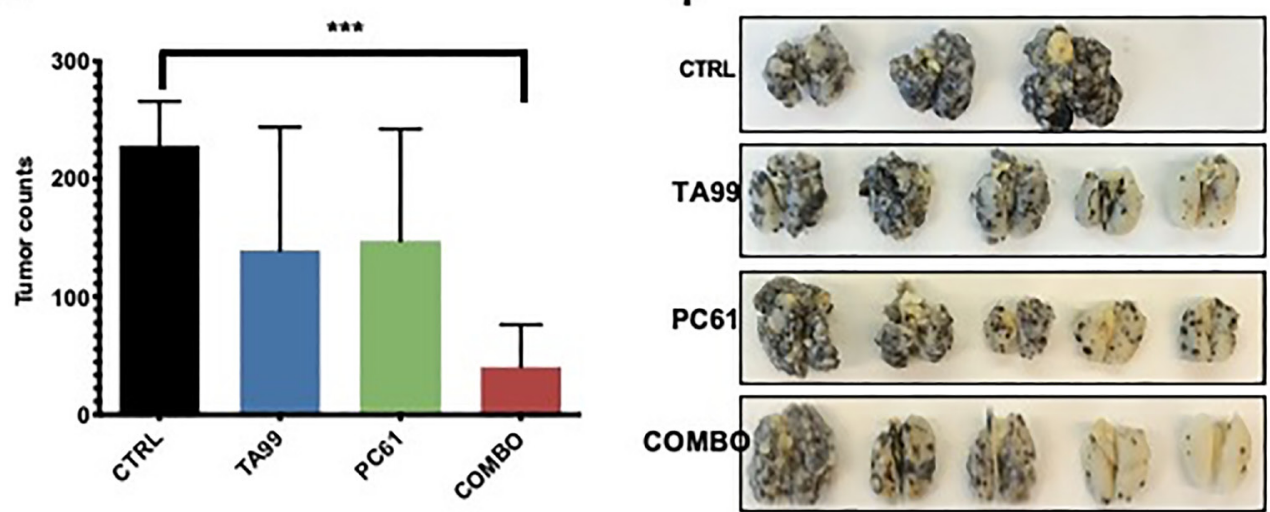

Figure 1: Depletion of Treg cells increased the anti-melanoma effects of TA99 mAb. C57BL/6 mice were treated with TA99 (anti-TYRP1) and PC61 (anti-CD25 depleting antibodies) beginning five days after s.c. or i.v. tumor cell injection (A). Subcutaneous tumor size was measured three times per week. Growth curves over time after grafting (days) are shown (B), and representative images of mice in different groups are shown (C). Flow cytometry analysis of these tumors showed a significant decrease in Treg cells infiltration (D). In the metastasis model, lungs were harvested on day 21 after tumor cell injection and metastatic nodules were counted (E). Images of lungs fixed in Fekete's solution are shown (F). The combination of TA99 mAb with antibody-dependent Treg depletion (anti-CD25) reduced the growth of subcutaneous tumors, and lung metastases burden; mean \pm SEM is shown. Significance was determined by two-way ANOVA with Bonferroni correction (B and D), or unpaired $t$ test (E). $n=3$ mice per group in (B-D), and 5 mice per group in (E) (representative from two experiments with similar results). ${ }^{* *} p<0.001 ;{ }^{* * *} p<0.0001$. 
We also tested the trametinib-mediated induction of melanosomal antigens in the trametinib-sensitive BRAF mutant cell lines YUMM1.7 and YUMM1.9, and found increased expression of TYRP1 (Figure 5C). Moreover, using qPCR, we found increased expression of TYRP-1, MITF and other melanosomal antigens (Figure 5D).

Since MEK inhibition resulted in the increased expression of the TA99 mAb target itself (TYRP1), as well as other melanosomal antigens, we treated B16 and YUMM1.9 subcutaneous tumor bearing mice with a combination with trametinib and TA99 (Figure 5E) and followed tumor growth. As predicted, when we treated the relatively trametinib-resistant B16 melanomas with TA99/trametinib, tumor growth in the single-agent treatment groups showed the same pattern as the control group. However, treatment with the combination TA99 and trametinib resulted in a significant reduction in tumor growth (Figure 5F, top). Moreover, after treatment of the more trametinib sensitive YUMM1.9 tumor bearing animals, we observed a significant reduction in tumor growth with either of the single-agent treatments and the eradication of subcutaneous melanomas in the majority of the animals treated with the combination of TA99 and trametinib (Figure 5F, bottom).

Based in our observations that the therapeutic effects of the anti-tumor antibodies TA99 can be enhanced by both ICB (Figures 3 and 4) and MEKi targeted therapy (Figure 5), we tested the triple combination in the BRAF mutant YUMM1.7 cell line (Figure 6A). This combination treatment with TA99, trametinib and ICB (with anti-PD1 or anti-CTLA4) mAb resulted in a significant reduction of tumor size compared to the control groups (Figure 6B).

\section{DISCUSSION}

Targeting tumor antigens with specific antibodies, such as anti-CD20 (rituximab), anti-HER2 (trastuzumab), anti-EGFR (cetuximab), is well-established and has been relatively successful in a number of cancers, via interference with cellular signaling, complement-mediated lysis, antibody-dependent cell-mediated cytotoxicity (ADCC), and/or antibody-dependent cell phagocytosis (ADDP) $[12-14,16,17]$. However, the use of these unmodified antibodies during the therapy of advanced solid tumors such as breast cancer, metastatic colorectal cancer and head and neck squamous cell carcinomas as monotherapy, result in a high proportion of tumors with primary and acquired resistance, and relatively low rates of lasting therapeutic responses [18-20].

Here, using mouse models of melanoma, we investigated the use of the TA99 mAb directed against TYRP1, a surface protein not involved in cellular signaling, whose administration we and others showed previously induced long-lasting FcR-dependent tumor specific immunity in the host, with kinetics consistent with an induced adaptive immune response against the tumor $[12,13,21]$. It has been shown that the use of TA99 enhances the beneficial effects of TYRP1 DNA [22] and peptide vaccination [23]. Further, TA99 in combination with IL-2 and T cell vaccines is effective for

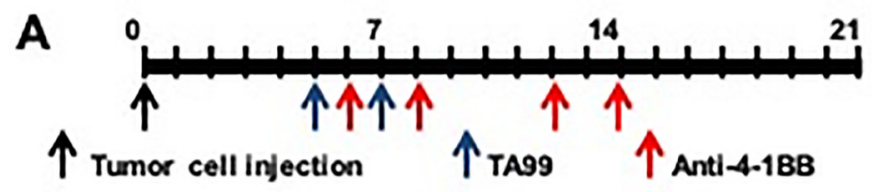

B
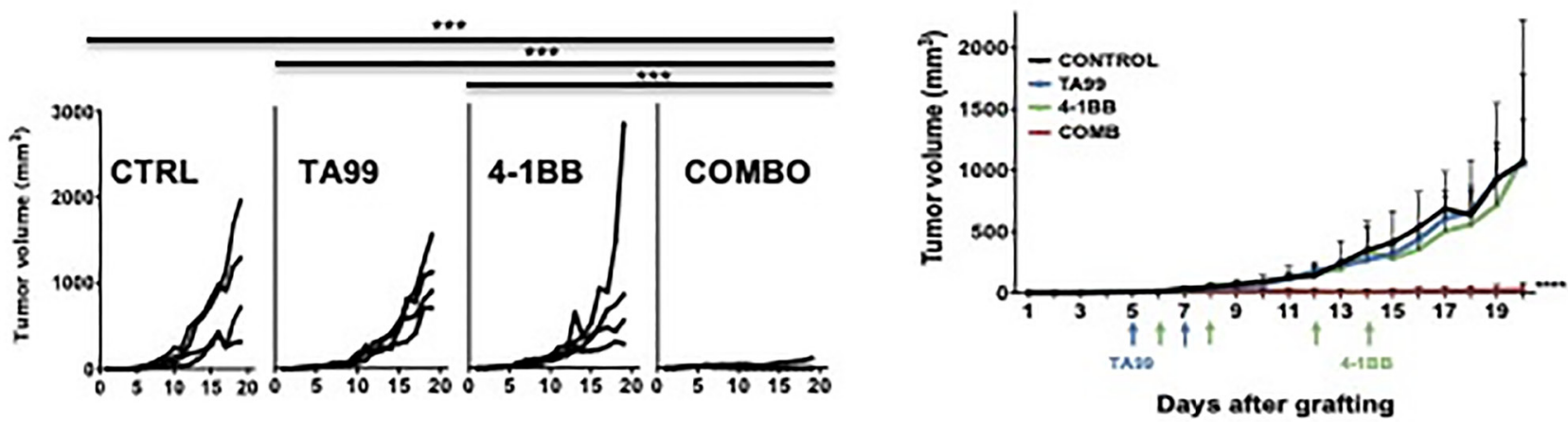

Figure 2: Anti-4-1BB/CD137 agonistic mAb enhanced the anti-tumor effects of TA99 in B16 subcutaneous melanomas. C57BL/6 mice were treated with TA99, anti-4-1BB agonistic antibodies or the combination beginning five days after B16 tumor cells subcutaneous inoculation (A). Combination treatment with TA99 and anti-4-1BB mAb led to eradication of B16 subcutaneous tumors (B). $5 \times 10^{4} \mathrm{~B} 16$ cells were injected (s.c.) and tumors were allowed to reach $65-80 \mathrm{~mm}^{3}$, and then treated as in (A), and combination treatment resulted in a significant reduction in tumor growth $(\mathbf{C})$. Data are presented as the mean $\pm \mathrm{SEM}$, and significance was determined by twoway ANOVA with Bonferroni correction $\left(n=4\right.$ mice per group in [B], and 5 mice per group in [C]). ${ }^{*} p<0.05 ;{ }^{* * *} p<0.0001$. 
the elimination of established tumors in the B16 model of melanoma [24].

Successful activation of the adaptive immune response by TA99 is also strictly regulated in vivo by inhibitory processes mediated by Treg cells and immune checkpoints. Here, we demonstrated that elimination of Treg strongly enhanced the anti-tumor effects of TA99 in the B16 models of subcutaneous solid tumors and lung metastases, suggesting the potential therapeutic advantage of the combination of specific anti-tumor antibodies with therapeutic strategies aimed at inhibiting other immunosuppressive processes, such as immune checkpoint blockade. Nonetheless, our (Left). observations indicated that elimination of $\mathrm{CD} 25^{+}$cells at early time points, i.e., day 4 after tumor cell inoculation induced a more rapid and larger outgrowth of B16 subcutaneous tumors. In agreement, it has been previously shown that $\mathrm{CD}^{+} \mathrm{T}$ cell help and IL-2 signaling were linked via $\mathrm{CD} 25$ up-regulation for the control of the expansion and differentiation of antigen-specific effector $\mathrm{CD}^{+} \mathrm{T}$

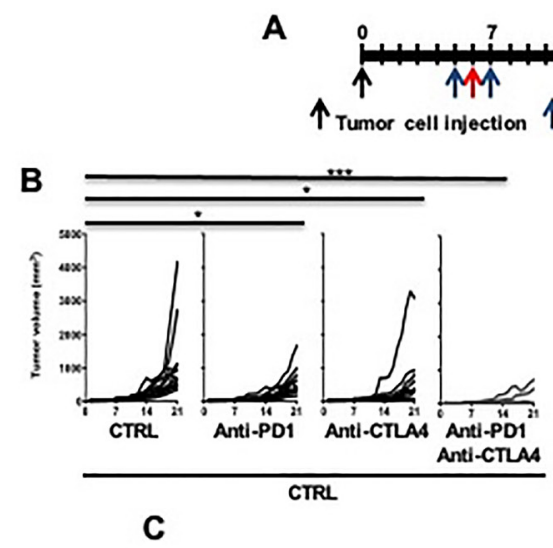

C

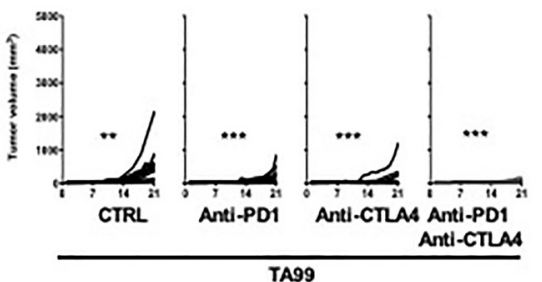

D
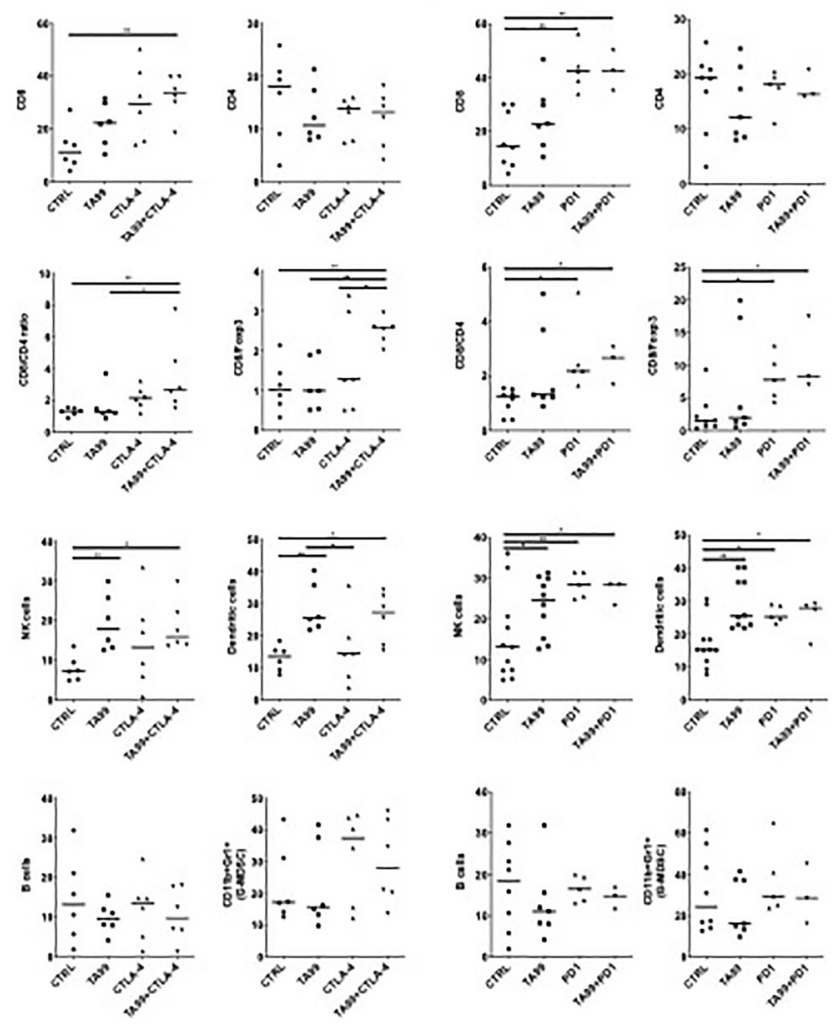

Figure 3: ICB enhanced the anti-tumor efficacy of TA99 in B16 subcutaneous melanoma. Treatment schedule of B16 melanoma bearing C57BL/6 mice with TA99 mAb alone or in combination with anti-PD1 or anti-CTLA4 (A). TA99 or ICB therapy alone resulted in modest tumor growth inhibition, which became highly significant when these therapeutic agents were combined (B). Differences in tumor growth were determined by two-way ANOVA with Bonferroni correction ( $n=10$ mice per group). ${ }^{*} p<0.05 ;{ }^{* *} p<0.001 ;{ }^{* * *} p<$ 0.0001. Left panel shows the comparison of different treatment with the untreated control group. Statistical significance on the right panel shows comparison with the no TA99 control group (left). At the end point, tumors treated with TA99 and anti-CTLA4 (C), and anti-PD1 (D) were collected after euthanasia and immunophenotyped by FACS analysis. Individual tumors are represented in the scatter plots and the median is shown. ${ }^{*} p<0.05 ;{ }^{* *} p<0.001 ;{ }^{* * *} p<0.0001$. 
cells [25]. Thus, we postulate that the early elimination of $\mathrm{CD}^{2} 5^{+} \mathrm{T}$ cells in our model results in the impairment of effector anti-tumor responses. Together, our findings indicate that the combination therapy with TA99 and the elimination of the regulatory signals resulting from the activation of anti-tumor immune responses could be an effective therapeutic strategy for the management of malignant melanoma.

Previous studies showed that the combination of TA99 with immunostimulatory molecules, such as toll-like receptor ligands and IL-2 has therapeutic effect dependent on a coordinated effect of the innate and adaptive antitumor immune response involving $\mathrm{CD} 8^{+} \mathrm{T}$ cells, $\mathrm{NK}$ and macrophages, and the expression of activating Fc $\gamma \mathrm{R}$, which increases the success rates of tumor-targeting TA99 in eliminating tumor cells [24, 26, 27]. Interestingly, we found that treatment with TA99 results in an increase in $4-1 \mathrm{BB}^{+}(\mathrm{CD} 137)$ cells, thus we postulated that the activation of the adaptive immune response induced by the treatment with TA99 could be enhanced by further cell activation to drive a robust effector response instead of tolerance. In line with previous reports in which the therapeutic activity of TA99 against established B16 tumors was enhanced with antibody-cytokine fusion (TA99-TNF) [28], we showed that agonist antibodies to $4-1 \mathrm{BB}$, a member of the TNFR family expressed on activated $\mathrm{T}$ and NK cells, synergized the anti-tumor effects of TA99. Further, it has been reported that agonistic activation of $4-1 \mathrm{BB}$ induced $\mathrm{CD}^{+}$and $\mathrm{CD}^{+}$ $\mathrm{T}$ cell activation, and prevented their activation-induced death, making these agonist antibodies an ideal therapeutic candidate to enhance anti-tumor immunity [29, 30]. In fact, preclinical and clinical studies have shown that the combination of the anti-EGFR antibody cetuximab with anti-4-1BB agonist leads to tumor resolution and prolonged survival, likely dependent on enhanced NK cell degranulation and cytotoxicity, in head and neck and colorectal cancers [29]. Together, we showed activation of the anti-tumor immune response with anti-4-1BB agonist antibodies can enhance the therapeutic effects of unmodified anti-tumor antibodies directed against nonsignaling molecules such as TA99.

The successful activation of innate and adaptive immune responses upon therapy with anti-tumor antibodies may be hindered by other regulatory mechanisms such as immune checkpoints. Monoclonal antibodies directed at blockade of immune checkpoint inhibitors are already in clinical use and have had a profound impact in the treatment of metastatic melanoma and other cancers. Here, we showed that the combination of ICB with antiPD1 or anti-CTLA4 antibodies with specific anti-tumor antibodies (TA99) results in an increased efficacy against B16 subcutaneous and lung melanomas, in agreement with previous reports showing that therapy with anti-HER2 antibodies synergizes with immune checkpoint blockade with anti-PD1 in mouse models of breast cancer [31]. Furthermore, as predicted from the current clinical data on anti-CTLA4 and anti-PD1 therapeutics [32, 33], we found that this combination resulted in a significant reduction of B16 tumors, which when combined with TA99 mAb therapy in a triple combination, resulted in eradication of solid subcutaneous tumors. It has been reported that
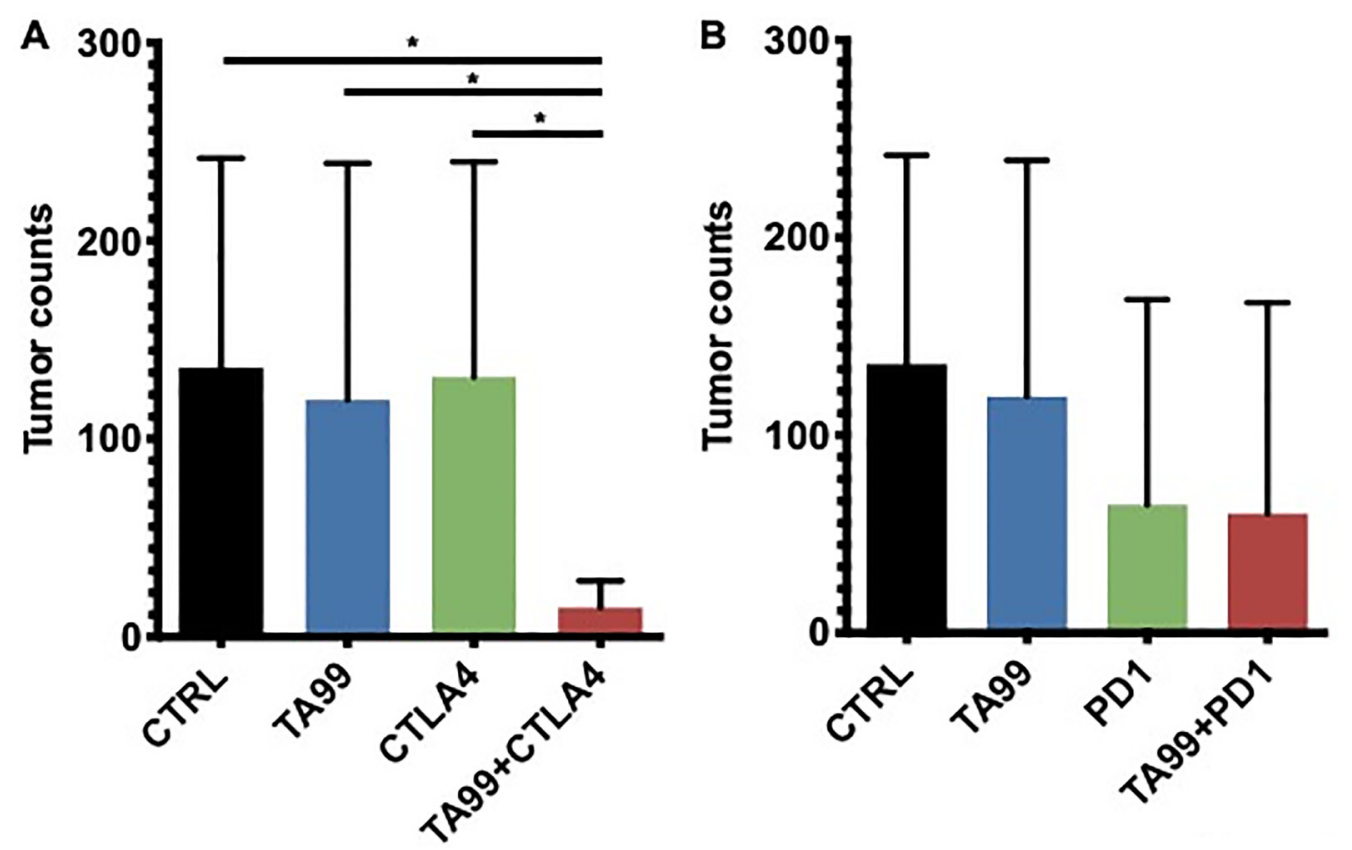

Figure 4: Combination therapy TA99/ICB reduced the lung tumor burden in the B16 model of metastases. C57BL/6 mice were inoculated B16 cells via tail vein injection, and treatment with anti-CTLA4 (A) or anti-PD1 (B) alone or in combination with TA99 was administered as described in Figure 3A. After 21 days, lungs were harvested and fixed, and metastatic nodules counted. The combination of TA99 mAb with immune checkpoint blockade reduced the lung metastases burden. Mean \pm SEM is shown. ${ }^{*} p<0.05$. 
eradication of large B16 tumors requires TA99, anti-PD1, and IL2 and a potent Tcell vaccine [24], however those tumors may be extremely aggressive since they are the result of a very high number of seeding B16 cells $(1 \times$ $10^{6}$ vs. $5 \times 10^{4}$ in our study). Moreover, in the B16 lung metastasis model, when we administered double ICB, we observed a significant reduction in the number of tumoral masses, however, the triple combination treatment did not improve the anti-tumor effect, as predicted from our observations in the solid tumors. This highlights the need for further studies to determine the correct timing and sequence of different therapeutic strategies, as suggested elsewhere [34].

Although we found that single treatment with TA99 did not result in significant changes in the recruitment of $\mathrm{CD}^{+}$and $\mathrm{CD}^{+} \mathrm{T}$ cells, the $\mathrm{CD}^{+} / \mathrm{Foxp}^{+}$ratio was increased in the tumors treated with the combination TA99/ICB. In agreement, it has been described that high doses of TA99 at early time points delays tumor growth, which is associated with increase in intratumoral $\mathrm{CD}^{+}$
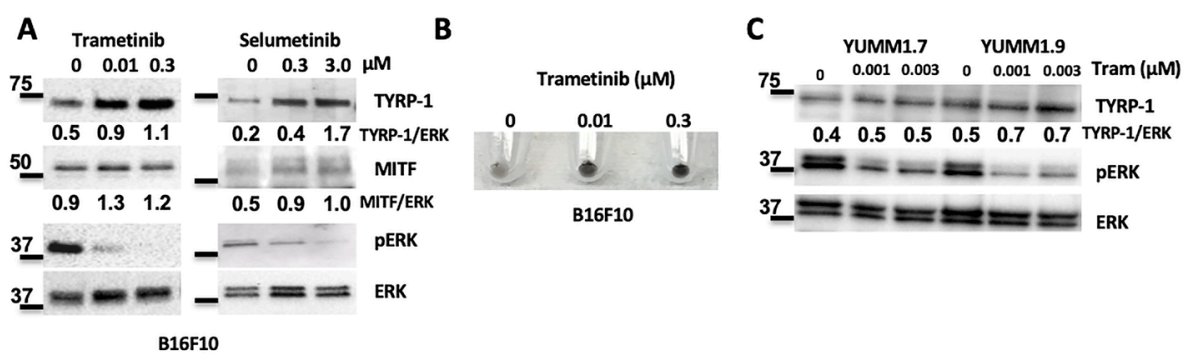

D
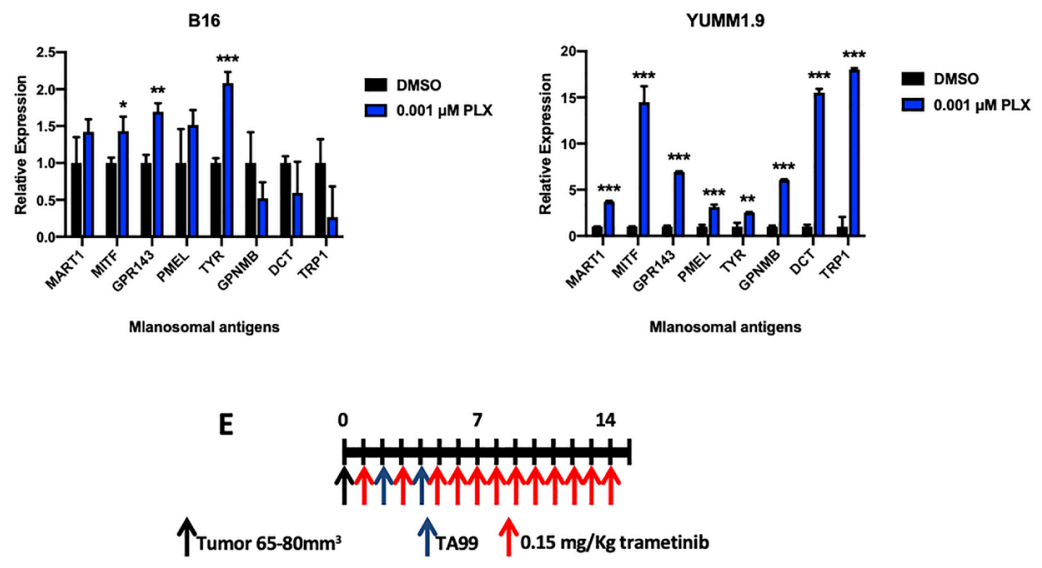

$\mathbf{F}$

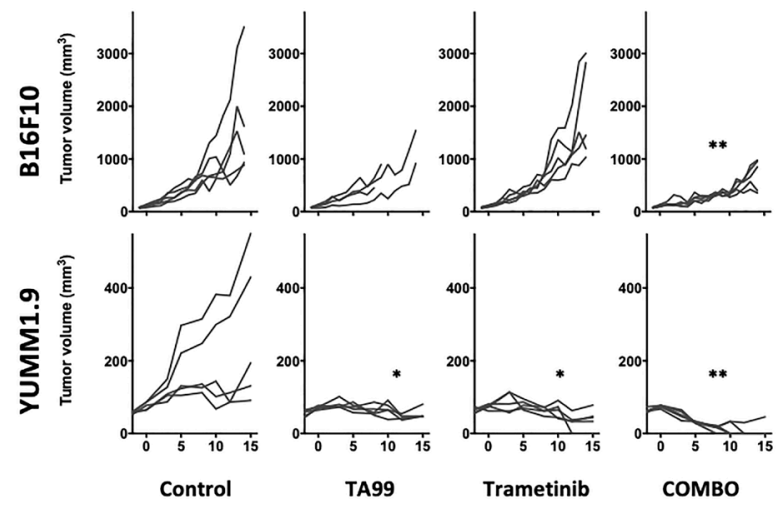

Figure 5: MEK inhibition enhances the anti-tumor effect with TA99 mAb. B16 cells were treated with MEKi for the indicated times and protein lysates were subjected to western blot analysis. MEK inhibition (as shown by dephosphorylation of ERK) resulted in increased levels of TYRP1 and MITF (A) and increased pigmentation (B). Trametinib also induced increased levels of TYRP1 in $\mathrm{BRAF}^{\mathrm{V} 600 \mathrm{E}}$-mutant $\mathrm{YUMM}$ cells $(\mathbf{C})$. RNA was prepared after treatment with trametinib, and increased expression of different melanosomal antigens was observed by qRT-PCR analyses. Relative expression of melanosomal antigens from technical triplicates is shown. Grey bars represent DMSO-treated controls, and blue bars represent melanoma cells after treatment with trametinib. Melanosomal antigens measured are: MART, MITF, GPR143, PMEL, TYR, GPMNB, DCT and TYRP1 (D) ${ }^{*} p<0.05 ;{ }^{* *} p<0.001 ;{ }^{* * *} p<0.0001$. Combined treatment with trametinib and TA99 (E) resulted in an enhanced anti-melanoma effect in both B16 and YUMM1.9 subcutaneous tumors in C57BL/6 mice (F). Differences in tumor growth were determined by two-way ANOVA with Bonferroni correction $\left(n=5\right.$ mice per group). ${ }^{*} p<0.05 ;{ }^{* *} p<$ 0.001. Comparison between the corresponding treatment group and the untreated control is shown. 
and $\mathrm{CD}^{+}$effectors, but it does not prevent exhaustion [21]. Moreover, we showed that treatment with TA99 induced a greater DC infiltrate in B16 tumors. This finding is consistent with reports indicating that treatment with the anti-EGFR antibody cetuximab results in an increased NK cell mediated ADCC, which makes the tumor cells or their antigens more susceptible to phagocytosis by DC $[16,17]$. Further, it has been reported that resistance to immunotherapy may be due in part to defective recruitment of DC, downregulation of antigen processing and presentation, and thus reduced cross-priming [24, 35-37]. In fact, the combination PD1/PDL1 blockade with agonist anti-CD27 in the B16 model resulted in an increased $\mathrm{CD} 8+\mathrm{T}$ cell expansion and effector function. Additionally, varlilumab (anti-CD27 agonist) has shown the same in a humanized model of lymphoma [36].

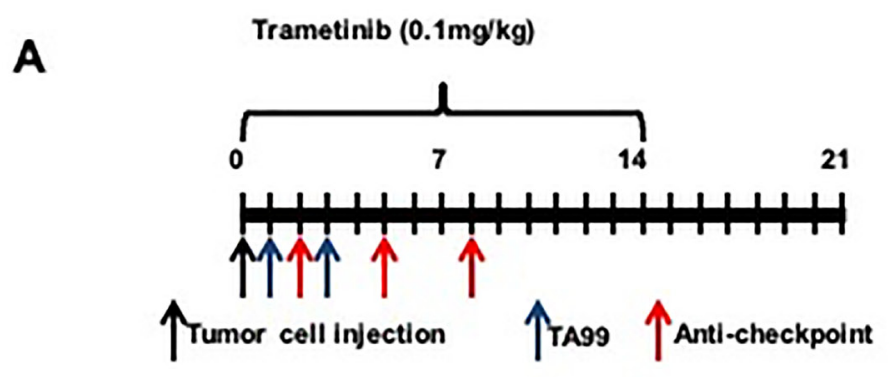

B

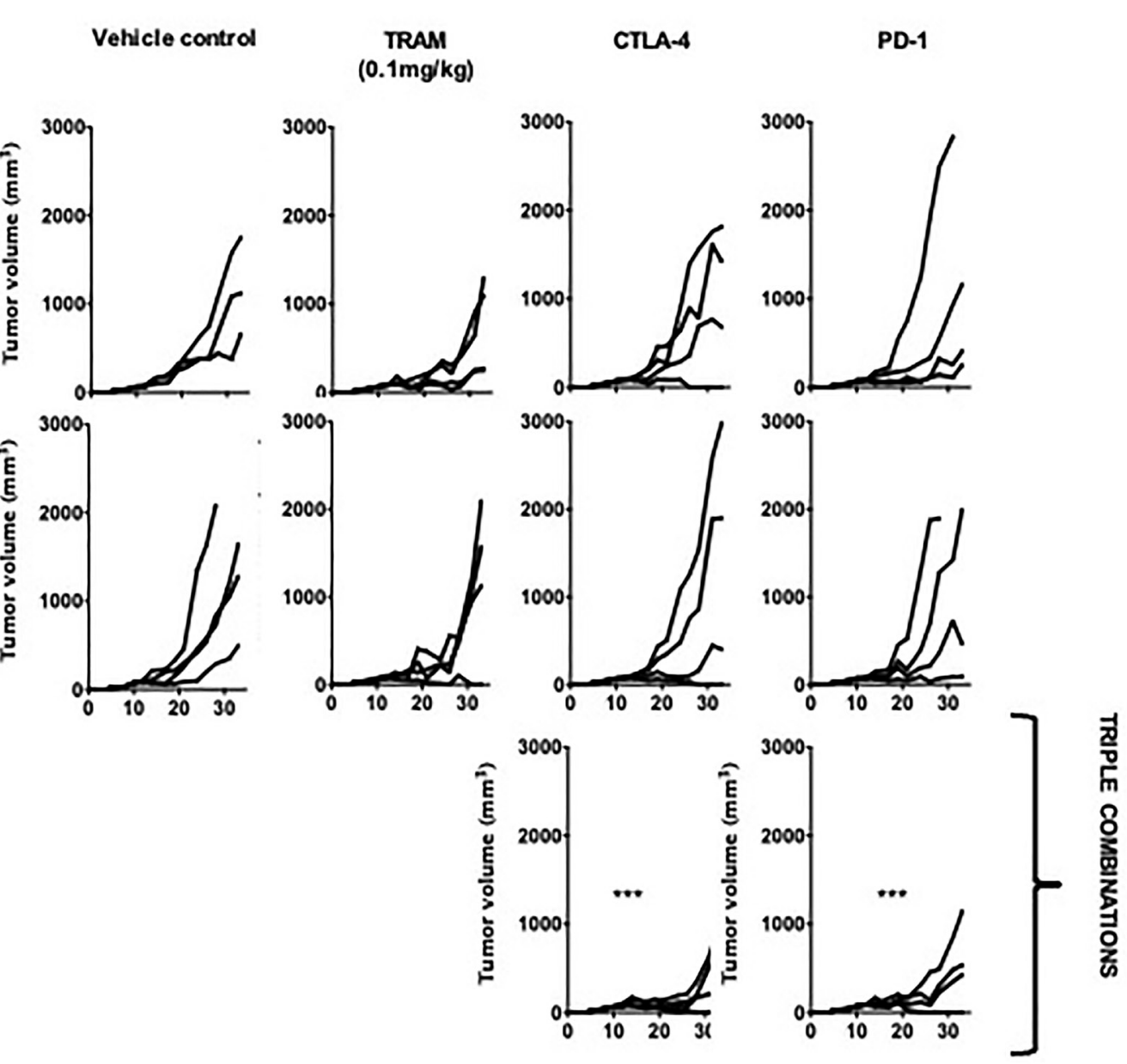

Figure 6: TA99 anti-tumor antibodies improved the outcome of treatment with combined targeted therapy and ICB in BRAF ${ }^{\mathbf{V}^{600 E}}$-mutant subcutaneous YUMM melanoma. C57BL/6 mice bearing YUMM1.7 subcutaneous melanoma were treated with MEKi, anti-immune checkpoint antibodies, or TA99 as single-agent therapies or in different simultaneous combinations (A) and differences in tumor growth were determined. The triple combination showed a significantly increased latency and reduced tumor size (B). Differences in tumor growth were determined by two-way ANOVA with Bonferroni correction ( $n=4$ mice per group). ${ }^{* * *} p<0.0001$. Both triple combinations show a significant increased control of tumor growth when compared with untreated control and with single and double agent treatment. 
Together, these findings underscore the potential for combination therapy with anti-tumor antibodies and ICB to improve therapeutic outcomes in patients with advanced melanoma.

There is evidence that chemotherapy and targeted therapy not only have direct cytostatic or cytotoxic effects on cancer cells, but also induce the activation of tumor-targeting immune responses, perhaps by increasing immunogenicity of malignant cells. Thus, the immunological effects of standard-of-care therapies can be desirable and useful during the establishment of successful combinatorial regimens [38]. It was previously described that BRAF and MEK inhibition induce the upregulation of a group of melanosomal proteins, known as the "melanosomal signature" in human BRAF ${ }^{\mathrm{V} 600 \mathrm{E}}$ cell lines and tumors [39-42], while activation of MAPK signaling reduces melanogenesis in B16 cells [43]. Accordingly, we found that in vitro treatment of the mouse BRAF ${ }^{\mathrm{V} 600 \mathrm{E}}$ cell lines YUMM1.7 and YUMM1.9, with the MEKi trametinib induced expression of the target of TA99 antibodies (TYRP1) and other melanosomal antigens. Moreover, B16 cells, which are relatively resistant to MEK inhibitors, also showed this response. We showed that MEKi-mediated induction of melanosomal antigens, particularly TYRP1, combined with the administration of anti-tumor antibodies resulted in an enhanced therapeutic effect in both the BRAF-WT and BRAF ${ }^{\mathrm{V} 600 \mathrm{E}}$ models. We postulate that this profound effect in the therapeutic outcome is due in part to MEKi-induced increase in tumor immunogenicity. The same phenomenon was previously described as a marker for positive response to anti-PD1 immunotherapy [44]. In addition, it was described that BRAF and MEK inhibition are capable of inducing a de-differentiation/re-pigmentation process depending on levels of MITF expression, especially in resistant cells [45]. Here, we demonstrated that increasing the expression of melanoma derived antigens with MEK inhibitors, in combination with an enhanced specific immune response through the use of anti-tumor antibodies, improved the response rates to $\mathrm{ICB}$ in the B16 and YUMM mouse models of melanoma. Thus, we postulate that inhibitors of the MAPK signaling pathway will reduce proliferation in sensitive cells and induce re-pigmentation in the survivors with an increased expression of TYRP1, which is the target of TA99 $\mathrm{mAb}$, therefore contributing to their elimination in our model.

Our therapeutic strategy is highly relevant to the treatment of melanoma patients, given the specificity of the antigen and its conservation across species [28]. Notably, a fully human anti-TYRP1 monoclonal antibody (20D7) that induced strong ADCC and suppressed human and mouse melanoma growth in subcutaneous and metastatic models in immunocompromised mice was described in the literature [46]. Moreover, 20D7 mAb was tested in patients with advanced melanoma who progressed on at least one line of treatment (Flanvotumab,
ImClone Systems). This phase I/Ib clinical trial showed that 20D7 was well tolerated (NCT01137006). In addition, one patient $(1 / 27)$ experienced a complete response, 10 patients (47\%) showed stable disease and 12 subjects (44\%) had progressive disease [47]. In melanoma, the use of BRAF/MEK inhibitors, depending on the driver mutations of the tumors [48], showed an OS of over 9 months in BRAF mutant tumors [49]. Moreover, therapy with immune checkpoint blockade, i.e., ipilimumab (antiCTLA4), nivolumab and pembrolizumab (anti-PD1), has been established as the standard-of-care for malignant metastatic melanoma. Immune checkpoint blockade has improved the median OS to 16.9 months, with a 4-year OS of $32.4 \%$ [15]. We postulate that using already approved forms of therapy (ICB and targeted therapy) may improve the efficacy of 20D7 unmodified anti-tumor antibodies.

Clinical trials with two different anti-4-1BB agonist antibodies, urelumab and utolimumab are ongoing [50]. Urelumab has shown high inflammatory liver toxicity, while utomilumab as a single agent has a more favorable safety profile $[50,51]$. However, utomilumab has an overall objective response of only $3.8 \%$ in solid tumors, which underscores the need of combination strategies to capitalize on the therapeutic potential of these antibodies. Moreover, there is an ongoing phase $1 \mathrm{~B}$ dose escalation clinical trial (NCT03364348) of anti-4-1BB agonistic in combination with trastuzumab (anti-HER2) in patients with HER2 ${ }^{+}$breast cancer.

Together with our preclinical data, these results invite further clinical investigation of unmodified antitumor antibodies in combination with ICB and targeted therapies, and may represent promising and innovative therapeutic interventions for the successful management of patients with advanced melanoma and other cancers.

\section{MATERIALS AND METHODS}

\section{Mice}

All animal experiments were conducted using 7-week-old female C57BL/6J mice purchased from The Jackson Laboratory. We used female animals to avoid scratching and wound healing as confounding variables in our studies. All animals were housed in groups of five animals/cage under a controlled environment of temperature and humidity and a $12 \mathrm{~h}$ light/dark cycle. Experimental procedures were carried out according to Columbia University institute of comparative medicine policies and an IACUC approved protocol.

\section{Cell lines and culture}

B16F10 (B16) cells were obtained from the Columbia University Skin Disease Resource-Based Center (epiCURE), and cultured at $37^{\circ} \mathrm{C}$ in $5 \% \mathrm{CO}_{2} / 95 \%$ air in DMEM supplemented with 10\% FBS and 1\% Penicillin/ 
Streptomycin. YUMM 1.7 and YUMM 1.9 BRAF ${ }^{\mathrm{V} 600 \mathrm{E}}$ mutant mouse melanoma cells [52] were obtained from Dr. Marcus Bosenberg (Yale University), and maintained at $37^{\circ} \mathrm{C}$ in $5 \% \mathrm{CO}_{2} / 95 \%$ air in DMEM/F12 medium supplemented with $10 \%$ FBS, $1 \%$ non-essential amino acids and 1\% Penicillin/Streptomycin. Cell lines tested negative for Mycoplasma infection (PCR) at the beginning of the study.

\section{In vivo antibodies and inhibitors}

The MEK inhibitor trametinib (GSK1120212) was purchased from Chemietek (Indianapolis, USA) and was dissolved to stock solutions in DMSO. For oral administration, a 1:10 dilution was prepared in hydroxypropyl methylcellulose and a maximum volume of $5 \mathrm{~mL} / \mathrm{kg}$ of body weight was given daily. Monoclonal antibodies used for in vivo treatment were purchased from BioXCell, and prepared in sterile DPBS (Gibco) for injection. Animals received i.p. injections of $200 \mu \mathrm{g}$ of anti-TYRP1 (TA99); $250 \mu \mathrm{g}$ of anti-CD25 (PC61); 200 $\mu \mathrm{g}$ of anti-4-1BB/CD137 (3H3); $100 \mu \mathrm{g}$ of anti-CTLA4 (9D9, IgG2b, depleting antibody), $200 \mu \mathrm{g}$ of anti-PD1 (RMP1.14), or isotype control antibodies as indicated for each experiment.

\section{Tumor studies}

The B16 model of melanoma has been described elsewhere [53]. Subcutaneous melanomas were generated by s.c. injection of $5 \times 10^{4} \mathrm{~B} 16$ tumor cells or $1 \times 10^{5}$ YUMM cells, and treatment was conducted as indicated in each experiment. Tumor growth was followed by measuring with a caliper, and volumes were calculated by using the formula $\left(d^{2} \times D\right) \times 0.52$, where $D$ represents the greatest diameter and $d$ represents the smallest diameter. Mice were euthanized when tumors exceeded $20 \mathrm{~mm}$ in diameter. For the lung metastasis model, $2 \mathrm{x}$ $10^{5} \mathrm{~B} 16$ melanoma cells were injected in the tail vein and tumors were allowed to grow for 21 days with or without treatment. At the end point, animals were euthanized and the lungs were fixed in Fekete's solution (55\% ethanol; $3 \%$ formaldehyde; $4 \%$ acetic acid) for contrast. Melanoma nodules were counted under stereotactic microscope (when tumors were too numerous to be counted, $>250$ was recorded). In all experiments, animal cages were randomly assigned to treatment groups (Excel random number generator).

\section{Flow cytometry analysis}

Subcutaneous tumors were resected at the end point and single-cell suspensions were prepared and enriched in Percoll gradient. Cells were stained with monoclonal antibodies to CD45-brilliant violet ${ }^{\mathrm{TM}} 605$, CD4-brilliant violet $^{\mathrm{TM}} 510$ (GK1.5), CD8a-brilliant violet ${ }^{\mathrm{TM}} 711$, Ly-6G/
Ly-6C(Gr-1)-brilliant violet ${ }^{\mathrm{TM}} 421$, CD11c-PE/Dazzle ${ }^{\mathrm{TM}}$, I-A/I-E(MHCII)-PerCP/Cy5.5 (BioLegend), CD19-FITC, NK1.1-PE, Foxp3-APC, CD11b-Alexa Fluor ${ }^{\circledR} 700$, and F4/80-Pe/Cy7 (Thermo Fisher Scientific). Cells were acquired using a BD Biosciences Fortessa flow cytometer (Cancer Center Flow Core Facility and Columbia Center for Translational Immunology). Analyses were done using FCS Express 6 software.

\section{Western blot analysis}

Cells were harvested in lysis buffer containing $50 \mathrm{mM}$ Tris (pH7.4), $150 \mathrm{mM} \mathrm{NaCl}, 1 \mathrm{mM}$ EDTA, 1\% IGEPAL, $10 \mathrm{mM}$ betaglycerophosphate, $50 \mathrm{mM}$ sodium fluoride, $1 \mathrm{mM}$ sodium orthovanadate, $1 \mathrm{ng} / \mu \mathrm{L}$ leupeptin, $1 \mathrm{ng} / \mu \mathrm{L}$ aprotinin, $1 \mathrm{ng} / \mu \mathrm{L}$ pepstatin $\mathrm{A}, 1 \mathrm{ng} / \mu \mathrm{L}$ AEBSF, and $10 \mathrm{nM}$ calyculin A (Sigma). Twenty $\mu \mathrm{g}$ of protein were resolved by SDS-PAGE, transferred to PVDF membranes, and immunoblotted with antibodies to TYRP1 (BioXcell laboratories), MITF (Invitrogen), ERK, and p-ERK (Cell Signaling technologies).

\section{Quantitative RT-PCR}

Mouse melanoma cells were treated with trametinib at the indicated concentrations. RNA from treated cells was isolated using RNeasy kit (Qiagen). cDNA was prepared using high-capacity cDNA reverse transcription kit (Applied Biosystems). Quantitative PCR was performed using PowerSYBR Green PCR Master Mix (Applied Biosystems) on the CFX96 Real-Time system (Bio-rad). Specific primer pairs for each gene were: TYRP1 (Fwd: CTTGGAGGTCCGTGTATTTG Rev: GACCGCATCAGTGAAAGTGT), MITF (Fwd: GCAAGAGGGAGTCATGCAGT Rev: GGGTCTGCA CCTTAAGGACT), GPNMB (Fwd: GGGCATAC ATTCCCATCTCG Rev: AGTGTTGTCCCCAA AGTTCCA), MART1 (Fwd: CTTGATGGACAAAAG GCGTC Rev: AGCATTCTAAAGCGAAACACCG), GPR143 (Fwd: GGCTGCCTGGGAATCGTTAT Rev:AGC CCCCATCAGTCTCTCAT), DCT (Fwd: GTCCTC CACTCTTTTACAGACG Rev: ATTCGGTTGTGACC AATGGGT), PMEL (Fwd: TGACGGTGGACCCT GCCCAT Rev: AGCTTTGCGTGGCCCGTAGC), TYR (Fwd: ACTTACTCAGCCCAGCATCC Rev: AGTGGTCCCTCAGGTGTTCC). The specificity of the primers was confirmed by melting curve analysis. Results were normalized to GAPDH and fold change of each gene was calculated by $2^{(\Delta \Delta \mathrm{Ct})}$. Experiments were performed in triplicate.

\section{Cell viability assays}

Changes in B16 cell viability upon treatment with MEK inhibitors in vitro were determined with the use of $3-(4,5$ - dimethylthiazol - 2 - yl $)-5$ - (3 
- carboxymethoxyphenyl) - 2 - (4 - sulfophenyl) - $2 \mathrm{H}$ tetrazolium (MTS) viability assays (Cell titer $96^{\circ} \mathrm{AQ}_{\text {ueous }}$ Non-Radioactive Cell Proliferation Assay, Promega), following the manufacturer's instructions. Briefly, $1 \times$ $10^{3} \mathrm{~B} 16$ mouse melanoma cells per well were seeded in 96-well plates. After allowing attachment (overnight incubation), cells were treated with fresh media containing the indicated concentrations of the corresponding drugs or vehicle control. After $72 \mathrm{~h}$ incubation, $20 \mu \mathrm{L}$ of MTS reagent was added and cells were incubated for additional $3 \mathrm{~h}$ before measuring absorbance at $490 \mathrm{~nm}$.

\section{Quantification and statistical analysis}

Data are presented as mean \pm SEM. Statistical differences were determined using Student's $t$ test, Kruskal-Wallis, with Bonferroni's post-test for multiple comparisons where appropriate. Statistical analyses were conducted using GraphPad Prism 6 software. Results were considered significant at $P \leq 0.05$.

\section{Abbreviations}

ADCC: Antibody-dependent cellular cytotoxicity; APC: Antigen presenting cells; 4-1BB: Tumor necrosis factor receptor superfamily member 9; BRAF: v-Raf murine sarcoma viral oncogene homolog B; CTLA4: Cytotoxic T-lymphocyte-associated protein 4; ERK: Extracellular signal-regulated kinases; ICB: Immune checkpoint blockade; mAb: Monoclonal antibody; MAPK: Mitogen-activated protein kinase; MEK: Mitogen-activated protein kinase kinase; MEKi: Mitogen-activated protein kinase kinase inhibitor; MITF: Microphthalmia-associated transcription factor; MTS: 3-(4,5-dimethylthiazol-2-yl)5-(3-carboxymethoxyphenyl)-2-(4-sulfophenyl)-2Htetrazolium; PD1: Programmed cell death protein 1; Treg: T regulatory cells; TYRP1: Tyrosinase-related protein 1.

\section{Author contributions}

Conception and design: RPL, AMC, RC; Development of methodology: RPL, SOE; Acquisition of data: RPL, SOE; Analysis and interpretation of data: RPL, SOE, AMC, RC; Writing, review, and/or revision of the manuscript: RPL, SOE, AMC; Study supervision: RPL, AMC, RC.

\section{ACKNOWLEDGMENTS}

We thank Wan Qing Huang (Jade), Emily Chan, Ming Zhang, and Wangyong Zeng for technical support.

\section{CONFLICTS OF INTEREST}

Authors have no conflicts of interest to declare.

\section{FUNDING}

This work was supported by NIH grant R01CA164309 to $\mathrm{RC}$ and $\mathrm{AMC}$, and Melanoma Research Alliance award 624220 to AMC and RPL. These studies used the resources of the Cancer Center Flow Core facility funded in part through center grant P30CA013696, and the Skin Disease ResourceBased Center, epiCURE through grant P30AR069632.

\section{REFERENCES}

1. Ribatti D. The concept of immune surveillance against tumors. The first theories. Oncotarget. 2017; 8:7175-7180. https://doi.org/10.18632/oncotarget.12739. [PubMed]

2. Greenman C, Stephens P, Smith R, Dalgliesh GL, Hunter C, Bignell G, Davies H, Teague J, Butler A, Stevens C, Edkins S, O'Meara S, Vastrik I, et al. Patterns of somatic mutation in human cancer genomes. Nature. 2007; 446:153-158. https:// doi.org/10.1038/nature05610. [PubMed]

3. Gyorki DE, Callahan M, Wolchok JD, Ariyan CE. The delicate balance of melanoma immunotherapy. Clin Transl Immunology. 2013; 2:e5. https://doi.org/10.1038/cti.2013.5. [PubMed]

4. Maio M. Melanoma as a model tumour for immunooncology. Annals of Oncology. 2012; 23:viii10-viii14. https://doi.org/10.1093/annonc/mds257. [PubMed]

5. Rawla P, Barsouk A, Hadjinicolaou AV, Barsouk A. Immunotherapies and Targeted Therapies in the Treatment of Metastatic Colorectal Cancer. Med Sci (Basel). 2019; 7:83. https://doi.org/10.3390/medsci7080083. [PubMed]

6. Lee YS, Johnson DE, Grandis JR. An update: emerging drugs to treat squamous cell carcinomas of the head and neck. Expert Opin Emerg Drugs. 2018; 23:283-299. https:// doi.org/10.1080/14728214.2018.1543400. [PubMed]

7. Abramson HN. Monoclonal Antibodies for the Treatment of Multiple Myeloma: An Update. Int J Mol Sci. 2018; 19:3924. https://doi.org/10.3390/ijms19123924. [PubMed]

8. Marini BL, Samanas L, Perissinotti AJ. Expanding the armamentarium for chronic lymphocytic leukemia: A review of novel agents in the management of chronic lymphocytic leukemia. J Oncol Pharm Pract. 2017; 23:502-517. https:// doi.org/10.1177/1078155216656929. [PubMed]

9. Prica A, Crump M. Improving CD20 antibody therapy: obinutuzumab in lymphoproliferative disorders. Leuk Lymphoma. 2019; 60:573-582. https://doi.org/10.1080/10 428194.2018.1498490. [PubMed]

10. Scott AM, Wolchok JD, Old LJ. Antibody therapy of cancer. Nat Rev Cancer. 2012; 12:278-287. https://doi.org/10.1038/ $\underline{\text { nrc3236. [PubMed] }}$

11. Yu S, Liu Q, Han X, Qin S, Zhao W, Li A, Wu K. Development and clinical application of anti-HER2 monoclonal and bispecific antibodies for cancer treatment. Exp Hematol Oncol. 2017; 6:31-15. https://doi.org/10.1186/ s40164-017-0091-4. [PubMed] 
12. Clynes R, Takechi Y, Moroi Y, Houghton A, Ravetch JV. Fc receptors are required in passive and active immunity to melanoma. Proc Natl Acad Sci U S A. 1998; 95:652-656. https://doi.org/10.1073/pnas.95.2.652. [ubMed]

13. Mancardi DA, Albanesi M, Jönsson F, Iannascoli B, Van Rooijen N, Kang N, England X, Daëron P, Bruhns MP. The high-affinity human IgG receptor Fc $\gamma$ RI (CD64) promotes IgG-mediated inflammation, anaphylaxis, and antitumor immunotherapy. Blood. 2013; 12:1563-1573. https://doi. org/10.1182/blood-2012-07-442541. [PubMed]

14. DiLillo DJ, Ravetch JV. Differential Fc-Receptor Engagement Drives an Anti-tumor Vaccinal Effect. Cell. 2015; 161:1035-1045. https://doi.org/10.1016/j. cell.2015.04.016. [PubMed]

15. Dobry AS, Zogg CK, Hodi FS, Smith TR, Ott PA, Iorgulescu JB. Management of metastatic melanoma: improved survival in a national cohort following the approvals of checkpoint blockade immunotherapies and targeted therapies. Cancer Immunol Immunother. 2018; 67:1833-1844. https://doi. org/10.1007/s00262-018-2241-x. [PubMed]

16. García-Foncillas J, Sunakawa Y, Aderka D, Wainberg Z, Ronga P, Witzler P, Stintzing S. Distinguishing Features of Cetuximab and Panitumumab in Colorectal Cancer and Other Solid Tumors. Front Oncol. 2019; 9:849. https://doi. org/10.3389/fonc.2019.00849. [PubMed]

17. Montaudié H, Viotti J, Combemale P, Dutriaux C, Dupin N, Robert C, Mortier L, Kaphan R, Duval-Modeste AB, Dalle S, De Quatrebarbes J, Stefan A, Brunet-Possenti F, et al. Cetuximab is efficient and safe in patients with advanced cutaneous squamous cell carcinoma: a retrospective, multicentre study. Oncotarget. 2020; 11:378-385. https:// doi.org/10.18632/oncotarget.27434. [PubMed]

18. Cunningham D, Humblet Y, Siena S, Khayat D, Bleiberg H, Santoro A, Bets D, Mueser M, Harstrick A, Verslype C, Chau I, Van Cutsem E. Cetuximab monotherapy and cetuximab plus irinotecan in irinotecan-refractory metastatic colorectal cancer. N Engl J Med. 2004; 351:337-345. https://doi.org/10.1056/nejmoa033025. [PubMed]

19. Kienle DL, Dietrich D, Ribi K, Wicki A, Quagliata L, Winterhalder RC, Koeberle D, Horber D, Bastian S, Kueng M, Saletti P, Helbling D, Baertschi D, et al. Cetuximab monotherapy and cetuximab plus capecitabine as first-line treatment in older patients with RAS- and BRAF wild-type metastatic colorectal cancer. Results of the multicenter phase II trial SAKK 41/10. J Geriatr Oncol. 2019; 10:304 310. https://doi.org/10.1016/i.jgo.2018.11.011. [PubMed]

20. Lavaud P, André F. Strategies to overcome trastuzumab resistance in HER2-overexpressing breast cancers: focus on new data from clinical trials. BMC Med. 2014; 12:1795-10. https://doi.org/10.1186/s12916-014-0132-3. [PubMed]

21. They L, Michaud HA, Becquart O, Lafont V, Guillot B, Boissière-Michot F, Jarlier M, Mollevi C, Eliaou JF, Bonnefoy N, Gros L. PD-1 blockade at the time of tumor escape potentiates the immune-mediated antitumor effects of a melanoma-targeting monoclonal antibody.
Oncoimmunology. 2017; 6:e1353857. https://doi.org/10.1 080/2162402x.2017.1353857. [PubMed]

22. Saenger YM, Li Y, Chiou KC, Chan B, Rizzuto G, Terzulli SL, Merghoub T, Houghton AN, Wolchok JD. Improved Tumor Immunity Using Anti-Tyrosinase Related Protein-1 Monoclonal Antibody Combined with DNA Vaccines in Murine Melanoma. Cancer Res. 2008; 68:9884-9891. https://doi.org/10.1158/0008-5472.can-08-2233. [

23. Ly LV, Sluijter M, van der Burg SH, Jager MJ, van Hall T. Effective Cooperation of Monoclonal Antibody and Peptide Vaccine for the Treatment of Mouse Melanoma. J Immunol. 2012; 190:489-496. https://doi.org/10.4049/ jimmunol.1200135. [PubMed]

24. Moynihan KD, Opel CF, Szeto GL, Tzeng A, Zhu EF, Engreitz JM, Williams RT, Rakhra K, Zhang MH, Rothschilds AM, Kumari S, Kelly RL, Kwan BH, et al. Eradication of large established tumors in mice by combination immunotherapy that engages innate and adaptive immune responses. Nat Med. 2016; 22:1402-1410. https://doi.org/10.1038/nm.4200. [PubMed]

25. Obar JJ, Molloy MJ, Jellison ER, Stoklasek T, Zhang W, Usherwood EJ, Lefrançois L. CD4+ T cell regulation of CD25 expression controls development of short-lived effector CD8+ T cells in primary and secondary responses. Proc Natl Acad Sci U S A. 2010; 107:193-198. https://doi. org/10.1073/pnas.0909945107. [PubMed]

26. Zhu EF, Gai SA, Opel CF, Kwan BH, Surana R, Mihm MC, Kauke MJ, Moynihan KD, Angelini A, Williams RT, Stephan MT, Kim JS, Yaffe MB, et al. Synergistic Innate and Adaptive Immune Response to Combination Immunotherapy with Anti-Tumor Antigen Antibodies and Extended Serum Half-Life IL-2. Cancer Cell. 2015; 27:489-501. https://doi.org/10.1016/j.ccell.2015.03.004. [PubMed]

27. Benonisson H, Sow HS, Breukel C, Claassens J, Brouwers C, Linssen MM, Fransen MF, Sluijter M, Ossendorp F, van Hall T, Verbeek JS. High Fc $\gamma$ R Expression on Intratumoral Macrophages Enhances Tumor-Targeting Antibody Therapy. J Immunol. 2018; 201:3741-3749. https://doi. org/10.4049/jimmunol.1800700. [PubMed]

28. Murer P, Kiefer JD, Plüss L, Matasci M, Blümich SL, Stringhini M, Neri D. Targeted Delivery of TNF Potentiates the Antibody-Dependent Cell-Mediated Cytotoxicity of an Anti-Melanoma Immunoglobulin. J Invest Dermatol. 2019; 139:1339-1348. https://doi.org/10.1016/j.jid.2018.11.028. [PubMed]

29. Kohrt HE, Colevas AD, Houot R, Weiskopf K, Goldstein MJ, Lund P, Mueller A, Sagiv-Barfi I, Marabelle A, Lira R, Troutner E, Richards L, Rajapaska A, et al. Targeting CD137 enhances the efficacy of cetuximab. J Clin Invest. 2014; 124:2668-2682. https://doi.org/10.1172/jci73014. [PubMed]

30. Chacon JA, Sarnaik AA, Pilon-Thomas S, Radvanyi L. Triggering co-stimulation directly in melanoma tumor fragments drives CD8 +tumor-infiltrating lymphocyte 
expansion with improved effector-memory properties. Oncoimmunology. 2015; 4:e1040219-3. https://doi.org/10 $.1080 / 2162402 \times .2015 .1040219$. [PubMed]

31. Stagg J, Loi S, Divisekera U, Ngiow SF, Duret H, Yagita H, Teng MW, Smyth MJ. Anti-ErbB-2 mAb therapy requires type I and II interferons and synergizes with anti-PD-1 or anti-CD137 mAb therapy. Proc Natl Acad Sci U S A. 2011; 108:7142-7147. https://doi.org/10.1073/pnas.1016569108. [PubMed]

32. Postow MA, Chesney J, Pavlick AC, Robert C, Grossmann K, McDermott D, Linette GP, Meyer N, Giguere JK, Agarwala SS, Shaheen M, Ernstoff MS, Minor D, et al. Nivolumab and Ipilimumab versus Ipilimumab in Untreated Melanoma. N Engl J Med. 2015; 372:2005-2017. https:// doi.org/10.1056/nejmoa1414428. [PubMed]

33. Hodi FS, Chesney J, Pavlick AC, Robert C, Grossmann KF, McDermott DF, Linette GP, Meyer N, Giguere JK, Agarwala SS, Shaheen M, Ernstoff MS, Minor DR, et al. Combined nivolumab and ipilimumab versus ipilimumab alone in patients with advanced melanoma: 2-year overall survival outcomes in a multicentre, randomised, controlled, phase 2 trial. Lancet Oncol. 2016; 17:1558-1568. https:// doi.org/10.1016/s1470-2045(16)30366-7. [PubMed]

34. Vanella V, Festino L, Trojaniello C, Vitale MG, Sorrentino A, Paone M, Ascierto PA. The Role of BRAF-Targeted Therapy for Advanced Melanoma in the Immunotherapy Era. Curr Oncol Rep. 2019; 21:76. https://doi.org/10.1007/ s11912-019-0827-x. [PubMed]

35. Chen PL, Roh W, Reuben A, Cooper ZA, Spencer CN, Prieto PA, Miller JP, Bassett RL, Gopalakrishnan V, Wani K, De Macedo MP, Austin-Breneman JL, Jiang H, et al. Analysis of Immune Signatures in Longitudinal Tumor Samples Yields Insight into Biomarkers of Response and Mechanisms of Resistance to Immune Checkpoint Blockade. Cancer Discovery. 2016; 6:827-837. https://doi. org/10.1158/2159-8290.cd-15-1545. [PubMed]

36. Buchan SL, Fallatah M, Thirdborough SM, Taraban VY, Rogel A, Thomas LJ, Penfold CA, He LZ, Curran MA, Keler T, Al-Shamkhani A. PD-1 Blockade and CD27 Stimulation Activate Distinct Transcriptional Programs That Synergize for CD8+ T-Cell-Driven Antitumor Immunity. Clin Cancer Res. 2018; 24:2383-2394. https:// doi.org/10.1158/1078-0432.ccr-17-3057. [PubMed]

37. Pitt JM, Vétizou M, Daillère R, Roberti MP, Yamazaki T, Routy B, Lepage P, Boneca IG, Chamaillard M, Kroemer G, Zitvogel L. Resistance Mechanisms to Immune-Checkpoint Blockade in Cancer: Tumor-Intrinsic and -Extrinsic Factors. Immunity. 2016; 44:1255-1269. https://doi.org/10.1016/j. immuni.2016.06.001. [PubMed]

38. Galluzzi L, Buqué A, Kepp O, Zitvogel L, Kroemer G. Immunological Effects of Conventional Chemotherapy and Targeted Anticancer Agents. Cancer Cell. 2015; 28:690 714. https://doi.org/10.1016/j.ccell.2015.10.012. [PubMed]

39. Reddy SM, Reuben A, Wargo JA. Influences of BRAF Inhibitors on the Immune Microenvironment and the
Rationale for Combined Molecular and Immune Targeted Therapy. Curr Oncol Rep. 2016; 18:42-9. https://doi. org/10.1007/s11912-016-0531-z. [PubMed]

40. Rose AAN, Annis MG, Frederick DT, Biondini M, Dong Z, Kwong LN, Chin L, Keler T, Hawthorne T, Watson IR, Flaherty KT, Siegel PM. MAPK Pathway Inhibitors Sensitize BRAF Mutant Melanoma to an Antibody-Drug Conjugate Targeting GPNMB. Clin Cancer Res. 2016; 22:6088-6098. https://doi.org/10.1158/1078-0432.ccr-161192. [PubMed]

41. Boni A, Cogdill AP, Dang P, Udayakumar D, Njauw CNJ, Sloss CM, Ferrone CR, Flaherty KT, Lawrence DP, Fisher DE, Tsao H, Wargo JA. Selective BRAFV600E Inhibition Enhances T-Cell Recognition of Melanoma without Affecting Lymphocyte Function. Cancer Res. 2010; 70:5213-5219. https://doi.org/10.1158/0008-5472.can-100118. [PubMed]

42. Knight DA, Ngiow SF, Li M, Parmenter T, Mok S, Cass A, Haynes NM, Kinross K, Yagita H, Koya RC, Graeber TG, Ribas A, McArthur GA, Smyth MJ. Host immunity contributes to the anti-melanoma activity of BRAF inhibitors. J Clin Invest. 2016; 126:402-403. https://doi. org/10.1172/jci84828. [PubMed]

43. Zhou J, Ren T, Li Y, Cheng A, Xie W, Xu L, Peng L, Lin J, Lian L, Diao Y, Jin X, Yang L. Oleoylethanolamide inhibits $\alpha$-melanocyte stimulating hormone-stimulated melanogenesis via ERK, Akt and CREB signaling pathways in B16 melanoma cells. Oncotarget. 2017; 8:56868-56879. https://doi.org/10.18632/oncotarget.18097. [PubMed]

44. Riaz N, Havel JJ, Kendall SM, Makarov V, Walsh LA, Desrichard A, Weinhold N, Chan TA. Recurrent SERPINB3 and SERPINB4 mutations in patients who respond to antiCTLA4 immunotherapy. Nat Genet. 2016; 48:1327-1329. https://doi.org/10.1038/ng.3677. [PubMed]

45. Czyz M, Sztiller-Sikorska M, Gajos-Michniewicz A, Osrodek M, Hartman ML. Plasticity of Drug-Naïve and Vemurafenib- or Trametinib-Resistant Melanoma Cells in Execution of Differentiation/Pigmentation Program. J Oncol. 2019; 2019:1697913. https://doi. org/10.1155/2019/1697913. [PubMed]

46. Patel D, Balderes P, Lahiji A, Melchior M, Ng S, Bassi R, Wu Y, Griffith H, Jimenez X, Ludwig DL, Hicklin DJ, Kang $X$. Generation and characterization of a therapeutic human antibody to melanoma antigen TYRP1. Hum Antibodies. 2007; 16:127-136. [PubMed]

47. Khalil DN, Postow MA, Ibrahim N, Ludwig DL, Cosaert J, Kambhampati SRP, Tang S, Grebennik D, Kauh JS, Lenz HJ, Flaherty KT, Hodi FS, Lawrence DP, Wolchok JD. An Open-Label, Dose-Escalation Phase I Study of AntiTYRP1 Monoclonal Antibody IMC-20D7S for Patients with Relapsed or Refractory Melanoma. Clin Cancer Res. 2016; 22:5204-5210. https://doi.org/10.1158/1078-0432. ccr-16-1241. [PubMed]

48. Nissan MH, Pratilas CA, Jones AM, Ramirez R, Won H, Liu C, Tiwari S, Kong L, Hanrahan AJ, Yao Z, Merghoub 
T, Ribas A, Chapman PB, et al. Loss of NF1 in cutaneous melanoma is associated with RAS activation and MEK dependence. Cancer Res. 2014; 74:2340-2350. https://doi. org/10.1158/0008-5472.can-13-2625. [PubMed]

49. Flaherty KT, Infante JR, Daud A, Gonzalez R, Kefford RF, Sosman J, Hamid O, Schuchter L, Cebon J, Ibrahim N, Kudchadkar R, Burris HA 3rd, Falchook G, et al. Combined BRAF and MEK Inhibition in Melanoma with BRAF V600 Mutations. N Engl J Med. 2012; 367:1694-1703. https:// doi.org/10.1056/nejmoa1210093. [PubMed]

50. Chester C, Sanmamed MF, Wang J, Melero I. Immunotherapy targeting 4-1BB: mechanistic rationale, clinical results, and future strategies. Blood. 2018; 131:49-57. https://doi.org/10.1182/blood-2017-06-741041. [PubMed]
51. Segal NH, He AR, Doi T, Levy R, Bhatia S, Pishvaian MJ, Cesari R, Chen Y, Davis CB, Huang B, Thall AD, Gopal AK. Phase I Study of Single-Agent Utomilumab (PF-05082566), a 4-1BB/CD137 Agonist, in Patients with Advanced Cancer. Clin Cancer Res. 2018; 24:1816-1823. https://doi.org/10.1158/1078-0432.ccr-17-1922. [PubMed]

52. Meeth K, Wang JX, Micevic G, Damsky W, Bosenberg MW. The YUMM lines: a series of congenic mouse melanoma cell lines with defined genetic alterations. Pigment Cell Melanoma Res. 2016; 29:590-597. https://doi.org/10.1111/ pcmr.12498. [PubMed]

53. Overwijk WW, Restifo NP. B16 as a mouse model for human melanoma. Curr Protoc Immunol. 2001; Chapter 20:Unit 20.1. https://doi.org/10.1002/0471142735. im2001s39. [PubMed] 